\title{
MORAL REALISM AND RELIANCE ON MORAL TESTIMONY
}

\author{
Joshua Blanchard
}

A thesis submitted to the faculty of the University of North Carolina at Chapel Hill in partial fulfillment of the requirements for the degree of Master of Arts in the Department of Philosophy.

Chapel Hill

2014

Approved by:

Geoffrey Sayre-McCord

Ram Neta

Ryan Preston-Roedder 
(C) 2014

Joshua Blanchard

ALL RIGHTS RESERVED 


\section{ABSTRACT \\ Joshua Blanchard: Moral Realism and Reliance on Moral Testimony (Under the direction of Geoffrey Sayre-McCord)}

Several philosophers have recently argued that there is something inappropriate about relying on moral testimony and that this has potential implications for the nature of morality. Specifically, some have thought that the inappropriateness of relying on moral testimony poses a special problem for moral realism, on which there are good grounds for predicting that such reliance is actually appropriate. In this paper, I argue that moral realism only predicts that reliance on moral testimony is epistemically appropriate, but that, as a metaethical thesis, it is silent on whether such reliance is morally appropriate. I argue further that there are no good grounds for thinking that reliance on moral testimony is in fact epistemically inappropriate. After presenting what I think is the best explanation for the moral inappropriateness of reliance on moral testimony, I argue that, contra several recent philosophers, it is only sometimes inappropriate. There are some cases where reliance on moral testimony is not only appropriate but both epistemically and morally important. 


\section{ACKNOWLEDGEMENTS}

I am grateful to Geoffrey Sayre-McCord, Ram Neta and Ryan Preston-Roedder for challenging discussions of the ideas in this paper. I would like to especially thank Geoff for setting aside considerable time to meet regularly with me and discuss multiple drafts.

Finally, I would like to thank my wife, Bethany, for always providing reliable moral testimony. 


\section{TABLE OF CONTENTS}

Section

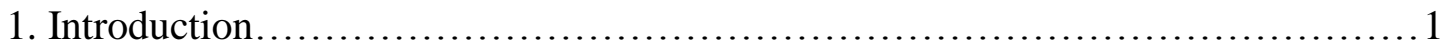

2. Skepticism about Reliance on Moral Testimony.................................. 3

3. Reliance on Moral Testimony: Epistemic and Moral Dimensions ................11

3.1. Reliance on Moral Testimony: the Epistemic Dimension.....................11

3.2. Reliance on Moral Testimony: the Moral Dimension........................14

4. Reliance on Moral Testimony: an All or Nothing Affair?.........................22

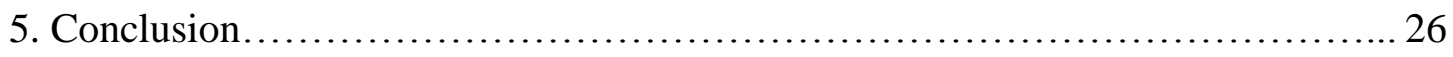

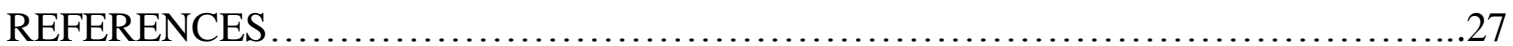




\section{Introduction}

Non-moral reliance: Bob wants to know whether beer is kosher for Passover. Because he has limited time and resources, Bob decides to forgo his own research into the matter and instead asks his friend, Sarah. Sarah devotes a considerable portion of her life to the practice and study of kashrut (Jewish dietary law). So when Sarah says, "No," Bob relies on Sarah's testimony. Henceforth Bob believes that beer is not kosher for Passover.

Moral reliance: Phil wants to know whether falsely testifying against one's neighbor for financial gain is morally permissible. Because he has limited time and resources, Phil decides to forgo his own research into the matter and instead asks his friend, Alan. Alan devotes a considerable portion of his life to the practice and study of morality. So when Alan says, "No," Phil relies on Alan's testimony. Henceforth Phil believes that falsely testifying against one's neighbor for financial gain is not morally permissible.

Much of the literature on moral testimony is motivated by the thought that while reliance on non-moral testimony is appropriate in ordinary cases, reliance on moral testimony inappropriate in structurally analogous cases. ${ }^{1}$ As Karen Jones (1999: 59) puts it, at first glance "it looks as though it is incumbent on us, as conscientious agents, to limit our dependency on the moral testimony of others as much as we can." ${ }^{2}$ Yet no such limitation seems to be incumbent upon us in non-moral matters. The above two cases illustrate the contrast of interest. In the case of non-moral reliance, Bob's limited time

\footnotetext{
${ }^{1}$ See Alison Hills (2013) for a review of the recent literature on moral testimony. Hills focuses on attempts to explain what distinguishes moral testimony from non-moral testimony, but she also considers attempts to show that the difference is merely apparent. Hills herself defends the "pessimistic" view that we have "strong reasons neither to trust moral testimony nor to defer to moral experts" (2009: 98). One of her arguments is that something she calls "moral understanding" is important in a way that mere "moral knowledge" is not.

${ }^{2}$ Jones goes on to defend reliance on moral testimony.
} 
and resources, combined with Sarah's reliability regarding kashrut, seem to permit Bob's reliance on Sarah's testimony. In contrast, Phil's limited time and resources, combined with Alan's reliability regarding morality, do not seem to permit Phil's reliance on Alan's testimony. Limited time and resources and the availability of reliable testimony are explicitly given in the two cases, so it is prima facie odd that the moral case produces intuitive resistance. Two related questions emerge from these observations. The first is obvious: can we justify (or explain away) our sense that reliance on moral testimony is in some way deficient relative to non-moral testimony? ${ }^{3}$ Second, if moral testimony is relatively deficient in some way, does this have any implications for our understanding of morality itself?

Several philosophers have linked the two questions. For example, Julia Driver (2006) argues that there is an apparent asymmetry between reliance on moral testimony and reliance on one particular form of non-moral testimony, namely aesthetic testimony. According to Driver, this poses a special challenge to those who think that moral norms are more objective than aesthetic norms. If morality is more objective than aesthetics, then we should expect that reliance on moral testimony would be less problematic than reliance on aesthetic testimony. Yet, reliance on moral testimony seems more problematic than reliance on aesthetic testimony. Philip Nickel (2001: 254), similarly, argues that the apparent inappropriateness of some cases of reliance on moral testimony presents cognitivists with the special challenge of explaining the inappropriateness in terms of special "norms for moral belief and action" beyond the norms for belief and

\footnotetext{
${ }^{3}$ Most philosophers who address this issue seek to justify the judgment of deficiency. But for two now-classic defenses of reliance on moral testimony, and deference to moral experts in particular, see Anscombe (1981) and Singer (1972). For recent defenses see Jones (1999), Sliwa (2012), and Driver (2006 and forthcoming).
} 
action simpliciter. Sarah McGrath (2011) links the two questions in a striking way by arguing that moral realism faces potential disconfirmation in light of its apparently inaccurate prediction that reliance on moral testimony can be appropriate.

Below I focus primarily on McGrath's argument. ${ }^{4}$ However, while this particular argument demands a response from the realist, realists should recognize that an apparent difficulty with reliance on moral testimony arises even without some of the special apparatus employed by McGrath. But I argue that the appearance of a difficulty relies on a crucial ambiguity. In order for the apparent inappropriateness of reliance on moral testimony to constitute a disconfirmation of moral realism, the inappropriateness must be epistemic rather than moral. I argue that reliance on moral testimony, while often morally inappropriate, is in fact not epistemically inappropriate. I then present a version of what I take to be the best account of the inappropriateness of reliance on moral testimony, which invokes principles that fall squarely within moral theory. Finally, I explain how the moral nature of the explanation itself suggests that recent skepticism about reliance on moral testimony is exaggerated, when in fact some reliance on moral testimony is both epistemically and morally important.

\section{Skepticism about reliance on moral testimony}

People's behaviors and attitudes vary in moral quality, and the moral realist insists that their moral beliefs vary in accuracy. Moreover, some people are especially good at figuring out moral matters; skill with moral inquiry comes in degrees. So moral realism seeks to accommodate what ordinary thought is arguably already committed to, namely,

\footnotetext{
${ }^{4}$ My main reason for this focus is that, as I explain in section 3, realism is committed to both the objectivity of moral norms and a cognitivist interpretation of moral discourse. My defense against McGrath's argument also functions, mutatis mutandis, as a defense of the sub-theses to which realism is committed.
} 
that some moral agents are especially reliable. Realism adds to ordinary thought that reliability in moral matters is at least partly cognitive reliability, precisely the sort of reliability enjoyed by many people in non-moral domains like the natural sciences. Such people get the moral facts right with a high frequency relative to the wider population. Finally, they are able to communicate these insights via truth-evaluable propositions. Prima facie, nothing seems to preclude us learning from such reliable individuals.

Here is where several philosophers voice skepticism. Moral realism explains moral reliability by positing the sorts of facts and processes that ground the development of expertise and reliance on testimony in other domains. It predicts that in moral matters, just as in non-moral matters, it is sometimes appropriate for us to defer to experts and to sometimes rely on the testimony even of those non-experts who are nevertheless more reliable than we are. But, on the contrary, it seems to many philosophers that reliance on moral testimony is in fact inappropriate.

Recent work by Sarah McGrath $(2009,2011)$ offers a clear and forceful development of this skepticism. McGrath thinks that the appropriateness of reliance on moral testimony is to be expected if morality is as the realist describes it. After all, reliance on testimony is perfectly appropriate in purportedly analogous non-moral domains. Yet,

there seems to be something odd or peculiar about my genuinely believing that capital punishment is wrong simply on the basis of your testimony, in a way that there is nothing similarly odd or peculiar about my believing that we should turn left simply on the basis of your testimony, or my believing that I owe a certain amount of money to the government on the basis of my accountant's testimony. ${ }^{5}$

\footnotetext{
"McGrath (2011: 113). Throughout her work, McGrath uses terms like "odd," "peculiar," "problematic," and "inappropriate" interchangeably. While in the main text I prefer "inappropriate," nothing in my paper turns on differences between these terms.
} 
As McGrath asks earlier in the paper, "If it is fine to defer to a tax specialist when one's finances get complicated, why is it not equally appropriate to defer to a moral specialist when one's life gets complicated in morally significant ways?"6 McGrath identifies this apparent asymmetry as a datum, and argues that a particularly strong flavor of such reliance is at issue. Specifically, McGrath singles out for attention what she calls "pure deference" (which I will call "pure reliance") and illustrates it with the following case:

I possess all of the nonmoral information thought relevant to the moral permissibility of the death penalty that you possess, and I have no special reason to think that my judgment is impaired. On the basis of this information and my own careful consideration of the issue, either it seems to me that the death penalty is morally permissible, or I remain undecided. Nevertheless, I judge that the practice is not permissible, on the basis of your testimony to that effect. ${ }^{7}$

In its simplest gloss, McGrath says that $\mathrm{S}$ purely relies when $\mathrm{S}$ "holds a view solely because another person holds that view." ${ }^{8}$ The focus on pure reliance rules out clearly unproblematic cases of reliance on moral testimony. For instance, reliance on another's testimony because she has privileged access to morally relevant non-moral information seems perfectly appropriate. McGrath also wants to rule out those cases where one relies in the weaker sense of merely accepting explicated advice. It seems perfectly appropriate, McGrath thinks (and I agree), when one listens to or takes into account what one's moral adviser says, and then acts only partly in light of her advice. While this sort of reliance is certainly a form of reliance on moral testimony, it is a mitigated form that seems

\footnotetext{
${ }^{6}$ McGrath (2011: 111). McGrath's paper focuses on deference to experts in particular. However, deference to experts is just a salient case of belief on the basis of reliable testimony. I will mainly speak in terms of reliance on testimony rather than deference to experts, but nothing in my reply to McGrath turns on this decision.

${ }^{7}$ McGrath (2011: 114).

${ }^{8}$ McGrath (2011: 113).
} 
unproblematic in the moral case. When one purely relies on testimony in some domain, $D$, however, one takes the testifier to have privileged information specific to $D$, and then simply accepts the information on her say-so. McGrath explains that "I in effect treat [the expert] as possessing purely moral information that I lack."9 Abstracting from the particularities of the example and formalizing a bit, pure reliance looks something like this:

Pure reliance: $S$ exhibits pure reliance toward $S^{*}$ with respect to a proposition $p$ in an domain of inquiry $D$ iff $S$ and $S^{*}$ are epistemic peers with respect to facts and abilities outside of $D$ relevant to $p$, and $S$ believes that $p$ solely on the basis of $S^{*}$ 's assertion that $p$.

In other words, neither $S^{*}$ 's $D$-dependent reasons, $S$ 's own consideration of the issue, nor any extra knowledge outside of $D$, factor into $S$ 's believing that $p$. Yet, while reliance on moral testimony of this stronger form seems inappropriate, pure non-moral reliance does not. As McGrath claims, “[I]t does not seem particularly important that one have much of a grasp on how exactly the tax specialist arrives at his estimate of what one owes: even if one treats his role in the process as essentially a black-box mechanism, nothing of significance is lost."10

Moral realism is thus threatened with the following argument:

1. If moral realism is true, then pure reliance on moral testimony is appropriate;

2. Pure reliance on moral testimony is never appropriate;

3. So, moral realism is false.

\footnotetext{
${ }^{9}$ McGrath (2011: 115, emphasis mine). An additional advantage of McGrath's focus on pure reliance is that it rules out consideration of cases involving judgments involving so-called thick terms. Such terms muddle some previous cases in the literature, e.g. Karen Jones' (1999: 59-62) example of a man, Peter, who cannot successfully apply the term "sexism." Jones claims that her example involves ignorance about the moral rather than descriptive component of the term "sexism," but in the actual case Peter fails to apply even the purely descriptive component. Driver (2006: 626) raises a similar complaint about the example.

${ }^{10}$ McGrath (2011: 113).
} 
This argument is stronger than the one McGrath officially offers. According to her, the problem for moral realism is not initially that pure reliance is inappropriate when it comes to moral issues; rather, pure reliance appears to be inappropriate, and there are no extant explanations of this appearance available to the moral realist. ${ }^{11}$ But if this is right, then one is immediately confronted with the stronger argument. ${ }^{12}$

McGrath invites us to see that someone who adopts a moral position "simply on the basis of ... testimony" seems to be doing something inappropriate, and the challenge to the realist is to explain this datum in a way friendly to realism. The sorts of cases considered by McGrath highlight an important asymmetry between moral and non-moral cases, and this asymmetry demands an explanation by the realist.

Before replying to McGrath's challenge, I want to address one potential complaint about the notion of pure reliance. One might think that the sort of reliance highlighted by McGrath is actually inappropriate in the non-moral cases as well; no one should purely rely on testimony in these cases, whether in their moral or non-moral versions. Something like this has recently been argued by Paulina Sliwa (2012). ${ }^{13}$ One might

\footnotetext{
${ }^{11}$ McGrath (2011: 116).

${ }^{12}$ Note that defenders of reliance on moral testimony frequently admit the appearance of asymmetry. For instance, while Jones (1999) defends reliance on moral testimony in some cases, her defense still admits an asymmetry between the moral and non-moral domains. Any defender of moral testimony who is also a moral realist must not only explain the asymmetry in a testimony-friendly way, but must do so in a realist-friendly way. Sliwa (2012) is one example where reliance on moral testimony is defended but the asymmetry is denied.

${ }^{13}$ See especially section 3 of that paper, with which I am in substantial agreement. Hills (2013: 558) classifies this view as a "debunking explanation" of the puzzling appearance of moral deference. Sliwa's main complaint about the typical cases is that the person relying on testimony is problematically ignorant rather than problematically reliant or deferential. She suggests a nonmoral case in which someone relies on a friend for knowing that there is an external world, and argues that here, too, the problem is a kind of ignorance rather than a kind of reliance.
} 
suspect that appropriate pure reliance only takes place only when we meet certain additional conditions left out of McGrath's characterizations, which themselves require one to have some genuine knowledge in the relevant domain, knowledge specifically relevant to the proposition in question. If we take seriously McGrath's allowance that one might think of a reliable testifier's "role in the process as essentially a black-box mechanism", then perhaps we ought to insist that pure reliance is inappropriate even in non-moral cases. Arguably, appropriate reliance at least requires that the one relying on testimony has done her due diligence in, first, determining that relative to herself the testifier is reliable and, second, that she genuinely comprehends the testimony itself. ${ }^{14}$ In other words, to appropriately rely on testimony one must meet something like the

Epistemic humility condition: $S$ must recognize $S$ 's own limitations relative to the testifier, $S^{*}$, in $D$;

and the

Comprehension condition: $S$ must understand $S^{*}$ 's assertion that $p$ to a degree sufficient for genuine belief.

The epistemic humility condition is in no need of defense. The comprehension condition is eminently plausible in light of what it would be like to fail to meet it. Suppose an historian tells $S$ that Abraham Lincoln was assassinated, but that $S$ hasn't the faintest idea to whom "Abraham Lincoln" refers, nor what it is for someone to undergo assassination. Suppose $S$ does knows that "Abraham Lincoln" refers to a person, and that "assassination" is something that can happen to a person. I claim that this negligible comprehension of the proposition Abraham Lincoln was assassinated actually precludes

${ }^{14}$ Cf. Jones (1999: 74), who says, "The evidential standards that must be met before trust in someone else's moral testimony is justified are high. This means that the morally indolent can take no particular comfort from a defense of the possibility of borrowing other people's moral knowledge." Cf. Driver (2006: 639-640) on the "markers" of moral reliability and the difficulty of acquiring them. 
$S$ 's genuinely deferring to a historian who asserts it. ${ }^{15}$ Notice that the comprehension condition, though it uses the term "understanding," does not require what several philosophers have in mind by the term. To understand that $p, S$ must know what it is for $p$ to be the case. $S$ may understand in this sense without understanding in the more sophisticated sense of knowing why it is that $p$, or enjoying access to the reasons for $p$. Such (albeit currently popular) conditions go well beyond what is required for meeting the comprehension condition. I suspect that the comprehension condition locates an unexplored middle ground between what has commonly been called "moral understanding" and the total ignorance with which the latter is usually contrasted. ${ }^{16,17}$ Accordingly, some might reasonably suspect that making explicit the satisfaction of these conditions in some of the central cases will mitigate our feeling of discomfort toward reliance on moral testimony. While such considerations lead some philosophers to

${ }^{15}$ If one is tempted by a distinction between deference de dicto and deference de re, then it should be clear enough that this paper is about deference de re.

${ }^{16}$ Nickel defends the view that moral knowledge requires moral understanding in the stronger sense, and defends a "recognition requirement" that says as much. An agent only understands moral claims "if their prima facie justificatory basis - consisting in prima facie reasons which support them - is clear to the agent. A person must grasp, by and large, what would count as support for a moral belief in order to understand it" (2001: 257-258). McGrath (2011: 123-126) criticizes this account (2011: 123-126). Driver identifies something like a moderated form of understanding, in which learning from a testifier requires one to understand "what he's saying", though she does not specify what this means other than to contrast it with the behaviors of a parrot (2006: 635). But Driver also requires that the receiver of testimony must have "the ability to [accept $\mathrm{p}$ on the basis of independent considerations]," and this is not a part of my account.

${ }^{17}$ I therefore reject John Hardwig's (1985: 345) embrace of the "paradoxical" idea that "B can know that $p$ even though he doesn't understand that p". Hardwig's proposal is, roughly, that when knowledge that $\mathrm{p}$ is based on expert opinion, the basis for this knowledge has the structure, "B knows that A knows that p" (where A is an expert or reliable testifier). Hardwig argues that, on pain of rejecting the existence of a large body of scientific knowledge, we must accept that "someone can know 'vicariously' - i.e., without possessing the evidence for the truth of what he knows, perhaps without even fully understanding what he knows" (348, emphasis mine). On the contrary, I may be able to know the proposition, "The sentence, 'p', is true"; but without understanding $\mathrm{p}$, I claim, it is not even possible to believe that $\mathrm{p}$, let alone know that $\mathrm{p}$. Cf. Hills (2009: 98n. 9). 
reject outright even the appearance of an asymmetry between moral and non-moral reliance on testimony, realists should appreciate that, no matter how much we pad the cases with due diligence on the part of the believer, the force of McGrath's datum remains in the final moment of pure reliance. It is fairly easy to generate examples in a way that takes account of the hard work someone must do before getting to the point of appropriately purely relying on non-moral testimony. Here is a non-moral case:

Josh recognizes that Ben is reliable with respect to myrmecology, because (i) Ben has a better record than Josh of reliably acquiring true myrmecological beliefs and (ii) Ben has a record of successfully explaining myrmecological matters to Josh. Josh wonders whether the insects referred to as "panda ants" are ants and doesn't feel like figuring it out for himself, so he asks Ben. Ben asserts that they are not (in fact, they are wasps). While Josh can't offer a biologically accurate explanation of why panda ants are not ants, he has a decent grasp of what it means that something is a wasp and not an ant. So, Josh believes that "panda ants" are not ants, on the basis of Ben's assertion.

Now contrast a moral case. To avoid the potential complications of cases involving testimony about currently contested practices, consider the following:

Billy recognizes that Suzy is an expert in morality, because (i) Suzy has a better record than Billy of reliably acquiring true moral beliefs and (ii) Suzy has a record of successfully explaining moral matters to Billy. Billy wonders whether lying about minor matters for fun falls under the general category of morally wrong and doesn't feel like figuring it out for himself, so he asks Suzy. Suzy asserts that it does. While Ben can't offer a morally accurate explanation of why lying about minor matters for fun is wrong, he has a decent grasp of what it means that something is wrong and not right. So, Billy believes that lying about minor matters for fun is morally wrong, on the basis of Suzy's assertion. ${ }^{18}$

These are still cases of pure reliance. Both Josh and Billy acquire their beliefs solely on the basis of another's testimony in the way described above. Yet what Josh does in the first case seems entirely appropriate, while what Billy does in the second case, though epistemically analogous, seems inappropriate. And while I've specified the sort of

${ }^{18}$ Sliwa (2012) specifically raises the objection that many cases in the moral testimony literature are undermined by their controversial subject matters. 
genuine (and even admirable) work that goes into both Billy's recognition that Suzy is reliable and his decision to rely on Suzy's testimony, this fails to mitigate the apparent badness of his reliance on Suzy. Cases like this show that no matter how much genuine epistemic and moral work is put in before the moment of pure reliance, the latter still strikes us as inappropriate when it comes to moral matters.

\section{Reliance on moral testimony: epistemic and moral dimensions}

Two important questions arise. First, does the inappropriateness of reliance on moral testimony really disconfirm realism? ${ }^{19}$ In order to do so, it is not enough that reliance on moral testimony is in some way or other inappropriate. Rather, reliance on testimony must be inappropriate in the very way that realism says it is appropriate. In section 3.1, I argue that moral realism predicts only that reliance on moral testimony is epistemically appropriate, and in section 3.2 that the datum only reveals moral inappropriateness. A second question is about the scope or reach of the datum. Although it is fairly easy to generate uncomfortable cases of reliance on moral testimony, should we think that such reliance is always inappropriate? In section 4, I argue that in some cases reliance on moral testimony is not only appropriate but important.

\subsection{Reliance on moral testimony: the epistemic dimension}

Consider the first question: insofar as moral realism predicts that reliance on moral testimony is appropriate, does it predict that such reliance is appropriate precisely in the way contravened by the datum? My claim in this subsection is that moral realism only deems reliance on moral testimony epistemically appropriate.

Moral realism is a very general thesis about the metaphysics, epistemology, and semantics of morality. On every version of realism, morality constitutes a domain of

\footnotetext{
${ }^{19}$ For ease of presentation I will henceforth speak only of "reliance" rather than "pure reliance."
} 
inquiry in which there are facts about what is morally good, bad, and so on. Moreover, extant forms of moral realism include epistemological proposals that attempt to explain how we enjoy epistemic access to moral facts. Conjoined with a cognitivist semantics, these very general features alone commit moral realists to the likelihood that people will vary in how accurately their beliefs fit with moral reality. And if there are people with more accurate moral beliefs than most, then, all else being equal, their testimony about moral matters will be correspondingly more trustworthy. ${ }^{20}$

The metaphysical and epistemological commitments of particular forms of moral realism are closely linked. On some naturalistic varieties of realism, for instance, one can be in causal contact with moral properties and develop well-justified statements and theories about them. ${ }^{21}$ These metaethical views suggest that moral inquiry into moral properties is in some ways parallel to empirical inquiry into chemical, physical, ... properties. Non-naturalistic moral realism, on the other hand, is sometimes criticized precisely because, even if there are non-natural moral properties, there are no available methods by which we can reliably acquire true beliefs about them. ${ }^{22}$ However, because these theories also typically posit a companion cognitive faculty to fit their non-naturalist metaphysics (e.g. intuition), philosophers who find the pill of non-naturalistic moral

\footnotetext{
${ }^{20}$ Moral realism is commonly divided along the two dimensions of semantics and metaphysics. Cf. Sayre-McCord (2012: 4365): "Moral realists maintain (1) that in making moral judgments ... people are purporting to report moral facts (and not just expressing their tastes or preferences) and (2) that there are such facts to report, so that some such claims are actually true and the world is, really, in those cases as claimed." For my purposes it is important to tease apart the claims that, on the one hand, there are moral facts (metaphysics), and that, on the other hand, we in fact enjoy reliable access to them (epistemology).

${ }^{21}$ A paradigmatic example of such a view is developed in Boyd (1988).

${ }^{22}$ A classic example of the complaint is Mackie (1977). See Bedke (2009) for a more recent argument against the epistemology of intuitionism in particular (which Bedke takes to be the last refuge for the non-naturalist).
} 
epistemology too bitter to swallow should nevertheless acknowledge that the expectation of variances in reliability and is not a special issue for non-naturalists. In this way, nonnaturalists will not vary from naturalists.

Moral realism so characterized attributes to the moral domain those very features that ground epistemically appropriate reliance on testimony in the non-moral domain. Whether a practice is epistemically appropriate is determined by characteristically epistemic norms and aims, e.g. norms and aims surrounding notions like belief, truth, justification, and knowledge. These are manifestly available in cases of reliance on moral testimony. If an agent is interested in moral truth, for example, she may to this end rely on the testimony of someone she knows to be reliable in moral matters. Nothing in the standard cases of moral testimony in any way blocks agents from finding out about the reliability of others. Likewise, that an individual's testimony is especially likely to be true is an excellent, positive justification for believing the content of her testimony. While we may criticize the recipient of this testimony in other ways, her behavior seems epistemically unproblematic. Insofar as testimony from a justified believer confers justification in general, there is nothing about the content of moral claims that can get in the way of this judgment. ${ }^{23}$ Our normative judgments about the datum do not themselves

\footnotetext{
${ }^{23}$ Philip Nickel (2001: 255) argues that there is a moral requirement to achieve moral "understanding" in the strong sense described above, but offers "the admission that sometimes one person comes to hold a correct moral belief because of another person's utterance." Nickel's paper is somewhat ambiguous with respect to whether these beliefs can constitute knowledge. At times he suggests that he is offering a norm of moral belief beyond whatever is the norm of belief simpliciter, and consequently his claim seems at least partly epistemic. But at other times he seems to be offering a consequentialist principle that simply says one should acquire moral beliefs in the way most likely to achieve good practical outcomes. Nickel writes, for example, "I will argue that in many circumstances, a person who relies on a moral utterance in this way will not be in a position to act in a morally good way" (256, emphasis mine). In any case, I am skeptical of the introduction of domain-specific norms of belief. The very idea of a norm of belief strikes me as a formal notion applying to beliefs in general, whatever their contents.
} 
lead us to conclude that the agent relying on moral testimony has somehow not gained a belief, or truth, or ordinary testimonial justification; rather, our judgments lead us to condemn something about the way in which the agent has (successfully) done this. But this strongly suggests that the norms violated in relying on moral testimony are simply not epistemic. ${ }^{24}$

Indeed, if there were something epistemically wrong with reliance on moral testimony, then we should expect widespread intuitive reactions to cases of this reliance to be different in nature than they in fact are. If the cases involving reliance on moral testimony were epistemically defective, then it might indeed seem that the receiver of testimony doesn't actually gain a moral belief; or that the receiver doesn't gain any reason for thinking the content of the testimony true; or, worse, that it is not actually possible to even offer moral testimony. Instead, the overwhelming sense one gets from the literature on moral testimony (and certainly from the cases themselves) is that reliance on moral testimony reveals something bad about the agent herself and, specifically, her behavior. This leads us to look not to epistemology or metaethics for an explanation of the datum, but to normative moral theory, on which moral realism is properly silent.

\subsection{Reliance on moral testimony: the moral dimension}

Because McGrath (like other philosophers allied in the campaign against reliance on moral testimony) motivates her argument primarily via cases, she avoids beginning with a positive explanation of why we should think reliance on moral testimony is in fact

\footnotetext{
${ }^{24}$ Some philosophers who criticize reliance on moral testimony frame the problem in a way that is incidentally friendly to realism precisely in the way I describe. For example, Hills' (2009) proposal is that, while one can gain moral knowledge via testimony, one cannot gain what she calls "moral understanding", and there are instrumental-moral reasons why the latter is important.
} 
inappropriate. Recall that her strategy is to observe that such reliance appears inappropriate, and then to argue that extant explanations do not explain this appearance in a realist-friendly way. Her cases are meant simply to reveal that - at least, in cases of a certain sort - we do think moral reliance is inappropriate, without probing why or how often we should think this. But we have now seen additional reasons for thinking that the datum does not show reliance on moral testimony to be epistemically inappropriate. This means that the inappropriateness of reliance on moral testimony cannot, by its nature, pose a problem for moral realism.

The best interpretation of the datum, that easily-generated cases of reliance on moral testimony seem unusually inappropriate, is that such reliance is morally inappropriate. Moral realism considered alone, as a metaethical thesis, is silent on whether reliance on moral testimony is inappropriate in this sense. To determine how and why it is morally appropriate, we need to explore normative, not metaethical moral theory.

We can plausibly explain cases of inappropriate reliance via considerations of moral integrity, considerations that fall squarely under the domain of normative moral theory. One ought to figure moral matters out for oneself, because doing so constitutes the achievement of a morally valuable status. This is a characteristically normative and not a metaethical position. Indeed, some philosophers have explicitly noted that our reactions to cases involving moral testimony seem to be characteristically moral reactions. For example, in considering a case where someone resists relying on moral testimony in favor of their own (as it turns out, incorrect) judgment, Karen Jones says that we can nevertheless see "why we might find morally attractive someone who resists 
such borrowing and refuses such trusting." 25 The resistance is attractive partly because moral belief and moral action are plausibly linked with notions like integrity. A concise statement of this linkage appears in Cheshire Calhoun's discussion of what she calls the “integrated-self” conception of integrity. Consider the following illuminating passage from Calhoun:

The integrated-self picture of integrity attaches value to autonomy. The project of becoming a person with integrity just is the project of becoming a fully autonomous person whose actions are determined by her self rather than by desires and values that are not truly her own. Having and acting on views of one's own is thus valuable not because of the sheer fact that they are one's own but because having and acting on views of one's own is integral to being an autonomous, free, and responsible being, which itself is valuable. ${ }^{26}$

This provides the basic framework for an elegant explanation of the actual inappropriateness of many cases of reliance on moral testimony, which in turns helps vindicate the appearance noted by McGrath.

Notice that the statement from Calhoun makes no mention of moral beliefs in particular. Rather, Calhoun simply notes that having and acting on beliefs of one's own, in general, contributes to one's status as autonomous. While I do not disagree with Calhoun here, it seems to me that one's status as autonomous, with respect to one's beliefs, varies in importance relative to the projects with which one identifies. For

\footnotetext{
${ }^{25}$ Jones (1999: 56). Jones' paper defends reliance on moral testimony in the context of the epistemology of trust and is primarily concerned to refute the thesis that relying on moral testimony is incompatible with autonomy. She argues that it is permissible to rely on moral testimony when this reliance is grounded in what she calls "wise trust," which is trust grounded in "good evidence about the person's character, about possible hidden agendas, and about whether she has the sort of experiences that contribute to the kind of competence we are counting on her to have" (73). Jones argues that these strong requirements are particular to the case of moral testimony and that "the appropriate default stance toward testifiers about morality is one of distrust" (72). See also my n. 14. My argument does not rely on distinguishing moral and nonmoral reliance on this way.

${ }^{26}$ Calhoun (1995: 255, emphasis mine).
} 
example, the chemist cares more about having and acting on her own beliefs about chemistry than does the layperson. In some sense the chemist, in virtue of adopting the project of becoming a chemist, incurs an obligation to achieve a relationship to chemistry in which many of her beliefs are not, or are no longer borrowed from others. Evidence for this comes from the thought that there is something inappropriate about a purported expert in a non-moral matter always needing to appeal to another's testimony in her own domain of expertise. Imagine, for instance, that you ask an evolutionary biologist why she accepts the theory of evolution, and she says, "Because Stephen Jay Gould accepted the theory of evolution," or, "Because most biologists accept the theory of evolution, though I know not why." Something is inappropriate about this answer for an evolutionary biologist. Thought it is acceptable (I argue) for a layperson to answer, "Because most biologists...", this answer is unacceptable for an expert. The best explanation for this is that the person for whom becoming a biologist is important, the person who has adopted the project of biology, is obligated to become more autonomous in the domain of biology.

So the appearance of inappropriate reliance on testimony is present in local, nonmoral domains in which the believer has adopted a personal project. On my view, reliance on moral testimony is distinctive partly because being "autonomous" in the moral domain is uniquely important to us. Most of us simply care more about achieving moral autonomy than we do about achieving chemical, historical, $\ldots$ autonomy. ${ }^{27}$ In

\footnotetext{
${ }^{27}$ There are similarities between my approach and Christine Korsgaard's (1996) view that we each can have a variety of "practical identities", but that one identity we are all, by necessity, rationally committed to is the practical identity constituted by a morally good person. My present claim is much weaker than Korsgaard's in that I am merely positing the descriptive psychological thesis that, in fact, overwhelmingly more of us take on (at least to some extent) something like "the moral project" than take on "the biological project," "historical project," etc.
} 
reacting to parallel cases of a person relying on, first, non-moral and then moral testimony, it is as if we were reacting to cases of a biologist relying on, first, nonbiological and then biological testimony. In this sense, we seem to take human beings to be subject to the demand for integrity in moral matters just as we take biologists to be subject to the demand for integrity in biological matters. But there is no way to understand this demand other than as a moral demand. It is not, as it were, a "metaethical" demand, whatever that would be.

This explanation is both independently plausible in its own right (that is, apart from metaethical disputes) and wholly consistent with moral realism. Two features in particular make the explanation independently plausible. The first and primary feature of the explanation that makes it plausible is that it links our normative disapproval of deference to the independently motivated descriptive thesis that we, in general, identify more closely with our moral positions than we do our chemical, historical, or other nonmoral positions. The absurd application of Calhoun's principle to chemical beliefs would have us say, in general, that "having and acting on views of one's own" in chemistry is "integral to being an autonomous, free, and responsible being." This is absurd because we do not take this general attitude toward chemistry. But our negative reactions to certain cases of moral reliance make sense if they arise from a more general attitude we take toward morality itself. Simply put, morality tends to matter to us. Indeed, deferring on moral matters can itself indicate a condemnable lack of investment in morality. Of course, deferring in chemical matters can indicate a lack of investment in chemistry, but 
not a condemnable lack; chemistry does not elicit from us the sense of importance enjoyed by morality. ${ }^{28}$

The second feature of the explanation that makes it plausible is that the proposal explains why the apparent inappropriateness of moral deference persists in both first- and third-personal cases. One may be struck by the fact that all of the cases considered have symmetrical first- and third-personal versions. I do not simply find inappropriate the idea of my reliance on moral testimony; I think of your reliance in the same way. On the current moral proposal, however, this feature is not at all odd. It would be odd if I found some behavior undignified in my own case, yet thought that my peers ought to nevertheless behave in this very manner. The cases that motivate skepticism about reliance on moral testimony are cases where either I or someone like me defers in her moral beliefs. Compare the (quite reasonable) aversion to being enslaved. Someone whose self-respect demands that she not consent to slavery ought to deem consent to

\footnotetext{
${ }^{28}$ Here I do not mean to embrace an overridingness thesis about moral norms (although I do independently embrace such a thesis). Rather, I merely intend to highlight the relative importance of morality to our identities. This is distinct from the kind of moral importance Jones appeals to in explaining the attractiveness of resisting moral testimony. For Jones, "The extra importance attached to moral judgments derives both from their close connection with action and from the importance of the concerns that morality addresses" (1999: 57-58). Later she invokes this kind of importance in her defense of reliance on testimony, writing, "If it is so very bad to make a moral mistake, then it would take astonishing arrogance to suppose that this supports a do-it-yourself approach" (66-67). But this is an appeal to the objective importance of the content of morality, rather than the importance of morality to us. The latter kind of importance helps explain why we might in some cases actually value false moral belief of one's own over true moral belief gained via testimony. Similarly, Nickel (2001: 261) argues that someone who relies on moral testimony is "more prone to error" in the moral domain than someone with "understanding" in his sense. But this overlooks the fact that those who need moral testimony most are those who, if they don't rely on moral testimony, will be systematically in error, and thus worse off error-wise than those who gain true moral beliefs via testimony. So this can't be a special problem with moral testimony per se. Finally, Driver notes that a "[moral] expert judgment becomes binding in a way that the aesthetic expert's judgment does not. I'm free to thumb my nose at Martha Stewart, but not so in the case of the moral expert" (2006: 640). This, too, is a point about moral demands themselves, rather than the importance of morality to us - whatever it demands.
} 
slavery similarly undignified when issued by others. Similarly, I resist the idea of relying on testimony for beliefs within local, non-moral identities I adopt (say, the identity of being a philosopher), but I likewise find inappropriate another philosopher's reliance on philosophical testimony.

But all of this is manifestly consistent with realism. That I ought not simply rely on moral testimony is consistent with it's being appropriate for me to do so vis-á-vis epistemic norms, and even with me gaining knowledge thereby. And it is the epistemic acceptability of reliance on testimony that is predicted by realism, not its moral acceptability.

It is possible that reliance on moral testimony isn't the only kind of reliance that evokes resistance in more than just local matters. Analogies that approach the generality of the moral cases can be developed in other sorts of cases. For instance, it may be possible and epistemically appropriate for me to merely rely on a reliable person's testimony about what the name for my child should be or what career I should pursue. I could even defer in these ways and get the correct answers. But there is something apparently bad about subordinating my beliefs and actions in this way. But this doesn't even so much as suggest that there isn't a truth about what I should do with my life, or what I should name my child. Rather, it is simply that these questions, and the answers to them, are just more closely bound up with my identity than mundane questions about various chemical compounds or historical events. I conclude that, for any matter integral to a status of central importance to us, reliance on testimony in that domain will frequently seem inappropriate. 
Finally, to the extent that the datum is explained in this way by normative moral theory, it is not just consistent with but positively friendly to moral realism. After all, moral realism says that there are moral facts and that we have access to these facts. Perhaps one of these facts is that it is important for human beings to figure moral matters out for themselves, whereas it is not important (or not as important) for them, in virtue of being human beings, to figure non-moral matters out for themselves. Metaethically speaking, there is nothing eccentric about this particular moral fact. Thus, while it is silent on the datum itself, moral realism is itself a framework for understanding the explanation of the datum. Among the moral facts are facts about what it is important for us to pursue with the kind of integrity identified by Calhoun, and so it is no wonder that our reaction to moral reliance is different from our reaction to non-moral reliance. ${ }^{29}$

Notice that this view is not vulnerable to McGrath's responses to other realist proposals. For instance, against proposals that point to the practical importance of moral positions, McGrath observes that reliance also seems inappropriate when performed with respect to historical moral judgments. But practical irrelevance does not imply personal irrelevance. In this way, my proposal does not "overestimate ... the extent to which ... moral judgments are tied to action., ${ }^{, 30}$ Also, the proposal avoids merely pushing the problem to the level of reasons. Against the proposal that what's wrong with reliance on moral testimony is that one fails to act for the right reasons, McGrath observes that it seems just as inappropriate to rely on testimony about reasons themselves (even though one could then proceed to act for the right reasons). My proposal explains that it is,

\footnotetext{
${ }^{29}$ Here it is worth noting that we may doubt the viability of a normative ground for a demand on what all of us should pursue. But once again, this is not a problem for realism.

${ }^{30}$ McGrath (2011: 136).
} 
indeed, morally important to have views of one's own - and this applies all the way down to the level of reasons.

\section{Reliance on moral testimony: an all-or-nothing affair?}

Recall the second question that I raised at the beginning of section 3 about the scope or reach of McGrath's datum. Although it is fairly easy to generate cases of inappropriate reliance on moral testimony, is such reliance always inappropriate? In this final section I offer some reasons for thinking it is not, and I give the beginnings of an explanation for why we might have suspected that it is.

The explanation offered above for the apparent inappropriateness of relying on moral testimony is notably not one which necessarily condemns all such reliance. Rather, the explanation identifies a morally good property of not relying on moral testimony. That property is something like what Calhoun calls "integrity"; it is what a person exhibits when she acquires and acts on views of her own. But acknowledging the moral importance of this property does not rule out the possibility that, in some cases, other, good properties of reliance on testimony may outweigh or override the bad.

At least two moral goods redound to the one who relies on moral testimony. First, one exhibits the epistemic humility characteristic of one who acknowledges the superior insight and abilities of another. Recall the epistemic humility condition that anyone must meet in order to justifiably rely on testimony. In relying on someone else's superior moral judgment, one rightly acknowledges one's limitations. And this is as it should be. As Jones writes, “There is a moral analogue of blindness. ... Those who lack the relevant perceptual skills in a given moral domain must rely on those who have sharper moral 
vision." ${ }^{31}$ Second, by acknowledge the superior insights of others and relying on them accordingly, one participates in relationships of moral and cognitive interdependence. Just as there is intrinsic value in having beliefs of one's own, and in developing and acting on views autonomously, so there is intrinsic value in respecting the authority and insight of others, and in developing and acting on views in solidarity with others. ${ }^{32} \mathrm{We}$ undoubtedly encounter situations in which these two goods outweigh or override the good of believing and acting autonomously.

So there is reason to think that philosophers who totally reject the appropriateness of relying on moral testimony overstate their case. ${ }^{33}$ But the very same apparatus via which I respond to McGrath helps explain why the datum might seem more far-reaching than it really is. If all cases of reliance on moral testimony seem inappropriate to some, this is perhaps due to the especially strong emphasis on autonomy and individualism in western ethical thought. In philosophical cultures that lack these emphases, we should not expect to find the same resistance to reliance on moral testimony. Recall again the epistemic humility condition. The potential difficulty of meeting this condition in the moral case highlights an important emotional asymmetry between moral and non-moral reliance. Epistemic humility is especially difficult in the case of morality, because we are more invested in acquiring views of our own than we are elsewhere. As described above, we tend to identify with our moral judgments in a way that makes it potentially difficult

\footnotetext{
${ }^{31}$ Jones (1999: 63).

${ }^{32}$ According to Linda Zagzebski (2012), we are actually committed, on pain of incoherence, to taking the testimony of others that $p$ as at least some reason to believe that $p$, provided we believe that others are sufficiently similar to ourselves in epistemically relevant ways. Zagzebski wields this insight in what she calls a prima facie case in favor of sometimes relying on moral testimony.

${ }^{33}$ Just as philosophers who totally embrace reliance on moral testimony overstate theirs.
} 
to take a posture of reliance toward another person in moral matters. Insofar as we lack the requisite virtue of epistemic humility in moral matters, moral reliance may seem distasteful even when it is not. This is simply not usually the case in non-moral matters. We do not, in general, tend to identify with our judgments in chemistry or mathematics; accordingly, we are not especially resistant to reliance on testimony in those domains. ${ }^{34}$

Accordingly, the best explanation for our difficulties in meeting the epistemic humility condition in moral but not non-moral cases is partly sociological. In general, western ethical thought is characterized by an especially strong emphasis on individuality and autonomy; even reflection on community itself is historically dominated by a vision in which otherwise isolated, largely self-interested agents coordinate mutual arrangements. ${ }^{35}$ It is not surprising that those of us working in traditions inclined toward a radically individualized, autonomous conception of moral agency frequently find reliance on moral testimony distasteful. On the other hand, we should expect that moral thought in traditions in which moral agents are not characterized exclusively in this way will be accordingly more amenable to the possibility of moral expertise and practices of moral deference. ${ }^{36}$

\footnotetext{
${ }^{34}$ Indeed, it is arguably better understood in non-moral domains that even experts must rely on each other's testimony. Here I agree with Hardwig (1985) that "epistemic dependence" is actually a pervasive feature of even expert scientific communities. It is harder, I think, for us to acknowledge our epistemic dependence on one another in moral matters.

${ }^{35}$ For a history of western moral philosophy explicitly structured by a narrative in which this conception finds its fruition in Kant, see Schneewind (1997).

${ }^{36} \mathrm{McGrath}$ at times acknowledges the possibility that intuitive reactions to the datum are culturally specific. "Perhaps this attitude [that pure moral deference is more problematic than non-moral deference] is common only in the relatively secular, post-Enlightenment West, and is more or less absent from many other cultures. Nevertheless, we can inquire as to what explains the common feeling that moral deference is problematic in a way that non-moral deference is not" (2009: 323). But if discomfort about moral deference is partly determined by these cultural
} 
I claim that this is exactly what we do find in Chinese philosophical thought influenced by Confucianism. ${ }^{37}$ Unsurprisingly, friendliness to deference to moral expertise in Chinese philosophy is combined with an (albeit quite abstruse) nonindividualistic conception of persons and their essential social roles. ${ }^{38}$ Similarly, we should expect subcultures within our own culture to be more amenable to reliance on moral testimony (and moral expertise in particular) in cases where their own practices and beliefs mitigate the exalted view of the self common in the history of western moral thought. It is unsurprising, therefore, that one of the classic defenses of reliance in moral matters from a western point of view comes from the Catholic philosopher Elizabeth Anscombe (1981). Religious communities in the Christian tradition tend to foster a relatively low view of the human exercise of moral capacities alongside a fairly complex infrastructure of epistemic interdependence on a variety of moral (and, of course, theological) issues. These systems are friendlier to what Karen Jones identifies as an upshot of her own trust-based defense of testimony.

If these reflections are along the right lines, then we can see another sense in which the virtuous person's virtue is essentially social: it is not just that the social sphere provides much of the domain for the exercise of virtue, nor just that it provides the conditions for sustaining it; rather, the knowledge that the virtuous person has is knowledge made available to her in part through epistemic dependence on others. ${ }^{39}$

\footnotetext{
factors, then our intuitive reactions are surely less probative with respect to moral realism than they would otherwise be.

${ }^{37}$ See Tiwald (2012) for an in-depth discussion of the Confucian philosopher Xunzi, who saw reliance on moral (and other) experts as both commonplace and justified. As far as I know, a connection has not yet been made between this material and the contemporary western discussions of moral testimony.

${ }^{38}$ See Brindley and references therein, and Shun (2004).

${ }^{39}$ Jones (1999: 78).
} 
This neglected value should not be seen as a threat to autonomy and the independent self, but as a reason for questioning its overriding import and exclusive centrality to our moral thinking. ${ }^{40}$

A moderated approach is desirable. On the one hand, it is important to recognize the asymmetry between the moral and non-moral domain with respect to how we conceive of our own identities. On the other hand, it is equally important to recognize that reliance on moral testimony is consistent with both the virtue of epistemic humility and the recognition of our thoroughgoing epistemic and moral interdependence.

\section{Conclusion}

The literature on moral expertise and moral testimony identifies an interesting asymmetry between the moral and non-moral domains due to morality's demand that we exhibit a certain kind of integrity in moral matters. But this asymmetry is no challenge to moral realism, because it is constituted by a moral, rather than epistemic difference. As such, the asymmetry is best explained by normative, rather than metaethical moral theory. In light of the best explanation of the asymmetry, we can see that the literature also reveals an unjustifiably extreme skepticism and resistance to reliance on moral testimony, owing to the very same commitment to integrity that underwrites our frequently justified skepticism. This commitment sometimes eclipses other, morally important phenomena.

\footnotetext{
${ }^{40}$ In a longer version of this paper, I do much more to explain and justify these appeals to classical Chinese and Christian philosophical thought.
} 


\section{REFERENCES}

Anscombe, Elizabeth (1981). "Authority in Morals," The Collected Philosophical Papers of G.E.M. Anscombe: Ethics, Religion, and Politics (Oxford: Oxford University Press), pp. 46-47.

Bedke, Matthew (2009). "Intuitive non-Naturalism Meets Cosmic Coincidence," Pacific Philosophical Quarterly, 90(2): 188-209.

Boyd, Richard (1988). "How to be a Moral Realist," in Geoffrey Sayre-McCord (ed.), Essays on Moral Realism (Cornell University Press), pp. 188-228.

Brindley, Erica. "Individualism in Classical Chinese Thought," Internet Encyclopedia of Philosophy, http://www.iep.utm.edu/ind-chin/, retrieved April 11, 2014.

Calhoun, Cheshire (1995). "Standing for Something," The Journal of Philosophy 92(5): 235-260.

Driver, Julia (2006). "Autonomy and the Asymmetry Problem for Moral Expertise," Philosophical Studies 128: 619-644.

Driver, Julia (Forthcoming). "Moral Expertise: Judgment, Practice, and Analysis,” Social Philosophy \& Policy.

Hardwig, John (1985). "Epistemic Dependence," The Journal of Philosophy 82(7): 335349.

Hills, Alison (2009). "Moral Testimony and Moral Epistemology,” Ethics 120: 94-127.

Hills, Alison (2013). “Moral Testimony,” Philosophy Compass, pp. 552-559.

Jones, Karen (1999). "Second-hand Moral Knowledge," The Journal of Philosophy 96(2): 55-78.

Korsgaard, Christine (1996). The Sources of Normativity (Cambridge University Press).

Mackie, J.L. (1977). Ethics: Inventing Right and Wrong (London).

McGrath, Sarah (2009). "The Puzzle of Pure Moral Deference," Philosophical Perspectives 23: 321-344.

McGrath, Sarah (2011). "Skepticism about Moral Expertise as a Puzzle for Moral Realism,” Journal of Philosophy 108: 111-137.

Nickel, Philip (2001). "Moral Testimony and its Authority," Ethical Theory and Moral Practice 4:253-266. 
Sayre-McCord (2012). "Moral Realism," in Hugh La Follette (ed.). The International Encyclopedia of Ethics (Blackwell), pp. 4365-4382.

Schneewind, J.B. (1997). The Invention of Autonomy: A History of Modern Moral Philosophy (Cambridge University Press).

Shun, Kwong-Loi (2004). "Conception of the Person in Early Confucian Thought," in Kwong-Loi Shun and David B. Wong (eds.), Confucian Ethics: A Comparative Study of Self, Autonomy, and Community (Cambridge University Press).

Singer, Peter (1972). "Moral Experts," Analysis 32(4): 115-117.

Sliwa, Paulina (2012). "In Defense of Moral Testimony," Philosophical Studies 158(2): 175-195.

Tiwald, Justin (2012). “Xunzi on Moral Expertise,” Dao 11: 275-293.

Zagzebski, Linda (2012). Epistemic Authority: A Theory of Trust, Authority, and Autonomy in Belief (Oxford University Press). 